\title{
AARC Clinical Practice Guideline: Effectiveness of Nonpharmacologic Airway Clearance Therapies in Hospitalized Patients
}

\author{
Shawna L Strickland PhD RRT-NPS AE-C FAARC, Bruce K Rubin MD MEngr MBA FAARC, \\ Gail S Drescher MA RRT, Carl F Haas MLS RRT FAARC, Catherine A O'Malley RRT-NPS, \\ Teresa A Volsko MHHS RRT FAARC, Richard D Branson MSc RRT FAARC, \\ and Dean R Hess PhD RRT FAARC
}

\begin{abstract}
Airway clearance therapy (ACT) is used in a variety of settings for a variety of ailments. These guidelines were developed from a systematic review with the purpose of determining whether the use of nonpharmacologic ACT improves oxygenation, reduces length of time on the ventilator, reduces stay in the ICU, resolves atelectasis/consolidation, and/or improves respiratory mechanics, versus usual care in 3 populations. For hospitalized, adult and pediatric patients without cystic fibrosis, 1) chest physiotherapy (CPT) is not recommended for the routine treatment of uncomplicated pneumonia; 2) ACT is not recommended for routine use in patients with COPD; 3) ACT may be considered in patients with COPD with symptomatic secretion retention, guided by patient preference, toleration, and effectiveness of therapy; 4) ACT is not recommended if the patient is able to mobilize secretions with cough, but instruction in effective cough technique may be useful. For adult and pediatric patients with neuromuscular disease, respiratory muscle weakness, or impaired cough, 1) cough assist techniques should be used in patients with neuromuscular disease, particularly when peak cough flow is $<270 \mathrm{~L} / \mathrm{min}$; CPT, positive expiratory pressure, intrapulmonary percussive ventilation, and high-frequency chest wall compression cannot be recommended, due to insufficient evidence. For postoperative adult and pediatric patients, 1) incentive spirometry is not recommended for routine, prophylactic use in postoperative patients, 2) early mobility and ambulation is recommended to reduce postoperative complications and promote airway clearance, 3) ACT is not recommended for routine postoperative care. The lack of available high-level evidence related to ACT should prompt the design and completion of properly designed studies to determine the appropriate role for these therapies. Key words: airway clearance therapy; ACT; chest physiotherapy; CPT; atelectasis; secretion clearance; percussion. [Respir Care 2013;58(12):2187-2193. (C) 2013 Daedalus Enterprises]
\end{abstract}

\begin{abstract}
Dr Strickland is affiliated with the American Association for Respiratory Care, Irving, Texas. Dr Rubin is affiliated with the Children's Hospital of Richmond at Virginia Commonwealth University, Richmond, Virginia. Ms Drescher is affiliated with the Washington Hospital Center, Washington DC. Mr Haas is affiliated with the University of Michigan Health System, Ann Arbor, Michigan. Ms O'Malley is affiliated with the Ann and Robert H Lurie Children's Hospital of Chicago, Chicago, Illinois. Ms Volsko is affiliated with Akron Children's Hospital, Akron, Ohio. Mr Branson is affiliated with the University of Cincinnati College of Medicine, Cincinnati, Ohio. Dr Hess is affiliated with Massachusetts General Hospital, Harvard Medical School, Boston, Massachusetts.
\end{abstract}

Dr Rubin has disclosed relationships with GlaxoSmithKline, Pfizer, InspiRx, Fisher \& Paykel, Teleflex, Philips Respironics, Novartis,

\begin{abstract}
Electromed, and Salter Labs. Ms O'Malley has disclosed relationships with Novartis and Pari Respiratory Equipment. Mr Branson has disclosed relationships with Covidien, Hamilton Medical, Advanced Circulatory Systems, Ikaria, Bayer, and Breathe Technologies. Dr Hess has disclosed relationships with Philips Respironics, Pari Respiratory Equipment, Covidien, Maquet, and Merck. The other authors have disclosed no conflicts of interest.
\end{abstract}

Correspondence: Shawna L Strickland PhD RRT-NPS AE-C FAARC, American Association for Respiratory Care, 9425 N MacArthur Boulevard, Suite 100, Irving TX 75063. E-mail: shawna.strickland@aarc.org.

DOI: $10.4187 /$ respcare. 02925 


\section{Introduction}

The mucociliary escalator and cough reflex defend the respiratory system by facilitating secretion clearance and preventing airways obstruction. Healthy individuals produce $10-100 \mathrm{~mL}^{1}$ of airway secretions daily, which are cleared by the centripetal movement of the mucociliary escalator. ${ }^{2}$ Many factors make it difficult to mobilize and evacuate secretions. The efficacy of the mucociliary escalator is impaired by aging, tobacco use, environmental exposures, and disorders such as bronchiectasis. ${ }^{3-5}$ Neurodegenerative conditions decrease the ability to cough effectively, leading to secretion retention. ${ }^{6-10}$

Airway clearance therapy (ACT), performed by respiratory therapists and other healthcare providers, is intended to aid secretion mobilization and expectoration, and to mitigate complications associated with secretion retention. ACT uses physical or mechanical means to manipulate air flow, to mobilize secretions cephalad, and to facilitate evacuation by coughing. ${ }^{11}$ Breathing maneuvers, gravity assisted drainage, manual techniques, and mechanical devices can be used in an effort to facilitate secretion mobilization.

Recommending, performing, and educating patients and families on ACT and secretion management are within the respiratory therapist's scope of practice. This therapy is also within the practice of physical therapists, nurses, and others. When possible, therapy should be matched to the patient's disease process, cognitive ability and preferences, the characteristics and limitations of the device or technique, and cost. Clinicians prescribing this therapy and those implementing the therapy must be familiar with the evidence supporting ACT techniques and devices, which is often limited. ${ }^{12,13}$

The purpose of this guideline, developed in conjunction with the systematic review by Andrews et al, ${ }^{14}$ is to provide guidance to clinicians in the identification, selection, and application of ACT techniques. These guidelines do not include the use of ACT in patients with cystic fibrosis (CF), as this has already been addressed. ${ }^{11}$

\section{Assessment of Evidence}

We sought to determine whether the use of nonpharmacologic ACT improves oxygenation, reduces length of time on the ventilator, reduces stay in the ICU, resolves atelectasis/consolidation, and/or improves respiratory mechanics versus usual care in 3 populations. The ACTs considered are listed in the Table. Because no high-level evidence was available and the recommendations are based on low-level evidence, we have not used a formal guideline development process such as the Grading of Recommendations Assessment, Development, and Evaluation (GRADE) system. ${ }^{15}$ Rather, the recommendations are based on a consensus of the committee, informed by a systematic review of the literature ${ }^{14}$ and clinical experience. The systematic review helped frame the issues and allowed for an identification of potential harms.

\section{Hospitalized Adult and Pediatric Patients Without Cystic Fibrosis}

Diseases such as pneumonia, bronchiectasis, COPD, and asthma have the potential to increase airway secretions, and endotracheal intubation can impair secretion clearance. Some patients are prescribed ACT for prophylaxis against symptomatic secretion retention (ie, ineffective gas exchange, atelectasis, dyspnea). Because of its historical prominence and frequent use, chest physiotherapy (CPT) has mistakenly been classified as the gold standard of ACTs. ${ }^{16-18}$

The systematic review found no evidence from randomized controlled trials (RCTs) to support the use of ACTs to improve oxygenation, reduce length of time on

Table. Airway Clearance Therapies Included in the Systematic Review

\begin{tabular}{|c|c|c|}
\hline Airway Clearance Therapy & Acronym & Definition \\
\hline Active cycle of breathing technique & $\mathrm{ACBT}$ & $\begin{array}{l}\text { Directed cough technique; relaxed diaphragmatic breathing and deep breathing } \\
\text { cycles followed by forced exhalation technique }\end{array}$ \\
\hline Chest physiotherapy & CPT & $\begin{array}{l}\text { External chest wall manipulation, which includes one of, a combination of, or } \\
\text { all of: percussion, vibration, and postural drainage therapy }\end{array}$ \\
\hline Forced exhalation technique & FET & Directed open-glottis cough technique; also called huffing \\
\hline High-frequency chest wall compression & HFCWC & $\begin{array}{l}\text { External manipulation through a vest or wrap worn by the patient, which is } \\
\text { connected to a device using bursts of air to compress the chest wall }\end{array}$ \\
\hline Intrapulmonary percussive ventilation & IPV & $\begin{array}{l}\text { Pneumatically powered, high-frequency short bursts of gas applied at the airway } \\
\text { opening (ie, mask encircling the nose and mouth, mouth, or tracheostomy tube) }\end{array}$ \\
\hline Mechanical insufflation-exsufflation & (none) & $\begin{array}{l}\text { Mechanically applied positive-pressure breath, followed by negative pressure } \\
\text { applied to the airway opening }\end{array}$ \\
\hline Positive expiratory pressure & PEP & $\begin{array}{l}\text { Exhalation against a fixed resistor that creates an increase in airway pressure; } \\
\text { includes oscillatory PEP devices such as Flutter and Acapella }\end{array}$ \\
\hline
\end{tabular}


the ventilator, reduce stay in the ICU, resolve atelectasis/ consolidation, and/or improve respiratory mechanics versus usual care in this population. ${ }^{14}$ Some studies suggest that intrapulmonary percussive ventilation (IPV) may decrease stay in the ICU for non-intubated patients with COPD, but insufficient high-level evidence exists to support a recommendation for this therapy. ${ }^{19,20}$

Guidelines from other groups also identified minimal evidence to support the use of ACT in hospitalized patients. ${ }^{21,22}$ Based on lower levels of evidence, some guidelines recommend forced expiratory technique (FET) for COPD patients, ${ }^{21}$ active cycle of breathing technique (ACBT), and autogenic drainage for the treatment of bronchiectasis in adults, ${ }^{22}$ or oscillating positive expiratory pressure (PEP) for patients with COPD. ${ }^{22}$

\section{Recommendations Supported by Low-Level Evidence}

1. CPT is not recommended for the routine treatment of uncomplicated pneumonia.

2. ACT is not recommended for routine use in patients with COPD.

3. ACT may be considered in patients with COPD with symptomatic secretion retention, guided by patient preference, toleration, and effectiveness of therapy.

4. ACT is not recommended if the patient is able to mobilize secretions with cough, but instruction in effective cough technique (eg, FET) may be useful.

\section{Adult and Pediatric Patients With Neuromuscular Disease, Respiratory Muscle Weakness, or Impaired Cough}

There are many causes of respiratory muscle weakness and impaired cough, including neuromuscular disease (NMD), spinal cord injury, primary neurologic conditions, and generalized weakness. NMD covers a wide range of disorders, with varying onset, rates of progression, and patterns of muscle involvement. Many NMDs eventually involve the respiratory muscles. ${ }^{23}$ Pulmonary complications are a well known cause of morbidity and mortality in these patients. ${ }^{24}$ Inspiratory muscle weakness decreases the ability to breathe deeply, and expiratory muscle weakness decreases the ability to generate the sufficient intrathoracic pressure during exhalation to cough effectively. While mucus production may be normal, some patients with bulbar muscle involvement may aspirate, leading to airway obstruction and infection. Pediatric patients have the additional burden of lower functional residual capacity, increased airway closure, and smaller airway diameter. ${ }^{23}$

No RCT met the criteria for inclusion in the systematic review. ${ }^{14}$ However, the American College of Chest Physicians, ${ }^{21}$ British Thoracic Society, ${ }^{22}$ American Associa- tion of Neurology, ${ }^{25}$ Centers for Disease Control and Prevention, ${ }^{26}$ and American Thoracic Society ${ }^{27}$ have published guidelines that recommend various ACTs in certain situations. These guidelines are based on low-level evidence, and patient benefit is indeterminate. Issues surrounding ACTs in this population include the necessity of a caregiver for assistance, poor technique, tolerance, and lack of effectiveness in some patients. ${ }^{21}$

Several guidelines recommended manual and mechanical cough assist procedures for patients who have a weak cough. 21,22,25,26,27 Mechanical insufflation-exsufflation was cautiously recommended for children with weak cough, ${ }^{22}$ strongly recommended in patients with Duchenne muscular dystrophy, 26,27 and recommended for patients with amyotrophic lateral sclerosis. ${ }^{25}$ Based on low-level evidence, it has been suggested that therapy for cough assist should be initiated when peak cough flow is $<270 \mathrm{~L} /$ min. ${ }^{27}$ Though frequently mentioned for management of patients with NMD, no high-level studies address CPT in this population. CPT is often not well tolerated or feasible in these patients. Previously reviewed guidelines do not report any recommendations related to CPT. ${ }^{21,22,25-27}$ PEP therapy is not recommended by any major medical society for the management of NMD patients. There are some RCTs involving IPV and high-frequency chest wall compression (HFCWC), but the sample sizes were small, and evidence to support or reject their use in this population is not sufficient. ${ }^{28-30}$

\section{Recommendations Supported by Low-Level Evidence}

1. Cough assist techniques should be used in patients with NMD, particularly when peak cough flow is $<270 \mathrm{~L} /$ $\min$.

2. CPT, PEP, IPV, and HFCWC cannot be recommended, due to insufficient evidence.

\section{Postoperative Adult and Pediatric Patients}

Postoperative pulmonary complications occur in approximately $7 \%$ of patients with normal preoperative lung function, and more than $70 \%$ of those with increased risk factors such as advanced age, history of smoking, obesity, preexisting chronic lung disease, obstructive sleep apnea, type and duration of surgery, extent and location of surgical incision, and use of a nasogastric tube. ${ }^{31-33}$ Upper abdominal and thoracic surgeries are associated with the highest complication rates. Postoperative pulmonary complications include atelectasis, respiratory failure, and airway infection. Although atelectasis is the most common complication, pneumonia is considered to be the main cause of increased mortality, and these can co-exist. ${ }^{34}$ Shallow breathing and weak cough lead to retained secretions and are thought to be a primary contributor. ${ }^{21,32}$ Therapies to 
address postoperative complications include lung volume expansion therapies (eg, incentive spirometry, intermittent positive-pressure breathing, CPAP) and secretion removal therapies (eg, CPT, HFCWC, IPV, PEP). ${ }^{35}$

Incentive spirometry is one of the most common therapies ordered for postoperative patients at risk for postoperative pulmonary complications and in those who develop pneumonia and atelectasis. The systematic review ${ }^{14}$ did not include incentive spirometry, but several recent meta-analyses have been published on this topic. Cochrane systematic reviews found no evidence of benefit for the routine use of incentive spirometry in patients following coronary artery bypass graft ${ }^{31}$ or upper abdominal surgery. ${ }^{32,36,37}$ Carvalho $^{34}$ et al came to similar conclusions in a review of 30 studies of patients recovering from abdominal, cardiac, and thoracic surgery.

The systematic review ${ }^{14}$ found that studies focused on CPT in this population did not demonstrate a reduction in the incidence of postoperative pulmonary complications, nor was there a decrease in hospital stay. Additionally, no improvement in pulmonary function $\left(\mathrm{FEV}_{1}, \mathrm{FVC}\right.$, or peak expiratory flow) was reported with the addition of CPT to routine patient care. ${ }^{38-44}$ The 2 studies of PEP therapy were contradictory, and therefore there is no clear evidence supporting the use of PEP therapy in this population. ${ }^{39,44}$ However, it has been well documented that early patient mobilization in this population can reduce the incidence of complications. ${ }^{45-47}$

The results of the systematic review ${ }^{14}$ are similar to other recent reviews. Pasquina et al $^{37}$ included 13 trials in a systematic review that compared physiotherapy to a nointervention control group, and concluded that routine physiotherapy was not justified. Another systematic review of strategies to reduce pulmonary complications after non-cardiothoracic surgery concluded that the evidence suggests that any type of lung expansion intervention is better than no prophylaxis, but that no modality was superior to the others, and combined modalities may provide additional risk reduction. ${ }^{48}$

Few if any of the studies in the postoperative population specifically evaluated airway clearance as an outcome. Given the low level of evidence for any ACT, no highlevel recommendations can be made at this time.

\section{Recommendations Supported by Low-Level Evidence}

1. Incentive spirometry is not recommended for routine, prophylactic use in postoperative patients.

2. Early mobility and ambulation is recommended to reduce postoperative complications and promote airway clearance.

3. ACT is not recommended for routine postoperative care.

\section{Questions to Consider When Selecting an Airway Clearance Technique or Device for an Individual Patient}

Despite the clinical observation that retained secretions are detrimental to respiratory function, and anecdotal associations between secretion clearance and improvements in respiratory function, there is a lack of high-level evidence to support any ACT. The results of the systematic review of RCTs by Andrews and colleagues ${ }^{14}$ are the same in each of the clinical settings evaluated. Specifically, for individuals without $\mathrm{CF}$, the ACTs reviewed provide small benefits in pulmonary function, gas exchange, oxygenation, and need for or duration of mechanical ventilation, but differences between groups were generally small and not significant.

The Andrews et $\mathrm{al}^{14}$ report does not mean that the device choice for airway clearance in a specific patient does not matter. Given a lack of evidence, we suggest the following process and clinical hierarchy of questions to determine the need for and technique used to perform airway clearance therapy. ${ }^{12}$

1. Investigate the rationale for use of airway clearance therapy. Does the patient have difficulty clearing airway secretions? Are retained secretions affecting gas exchange or lung mechanics? Rather than focusing on the volume of expectorated secretions, attention should be placed on the difficulty the patient is having when attempting to mobilize and expectorate airways secretions. Available evidence does not support routine airway clearance therapy in postoperative patients, mechanically ventilated patients, or patients with COPD.

2. Evaluate the potential for adverse effects of therapy. Which therapy is likely to provide the greatest benefit with the least harm? The review by Andrews et al suggests that the risk of harm associated with the usual ACTs is low, although complications may be under-reported. ${ }^{14}$

3. Determine the cost of the therapy. What is the cost of the therapy in terms of the device cost and clinician time to apply or supervise the therapy? ACTs can be time consuming for hospital staff. Some devices are expensive for the equipment and supplies. This is particularly important when selecting a device or techniques to be used at home.

4. Inquire about patient preferences. What factors are important to the patient with regard to performing airway clearance therapy? Lacking high-level evidence that any technique is superior to another, patient preference is an important consideration.

When a decision is made to prescribe airway clearance therapy for a patient, the expected outcome and treatment period should be clearly articulated. Desired outcomes or goals for therapy might include an increased (or decreased) volume of expectorated sputum, an improvement in gas exchange, an improvement in radiographic findings, or an 
improvement in patient-reported symptoms such as dyspnea. If the therapeutic goal is not achieved in the specified time, the therapy should be discontinued. Performing ACT with an ambiguous clinical outcome and continuing the therapy without evidence of benefit is a waste of resources. An $n$-of- 1 construct (multiple crossover studies in one individual) is attractive, but might be difficult to implement in the acute care setting. ${ }^{49,50}$

When evidence from high-level RCTs is not available, decisions may be made based on clinical judgment. For example, there is a strong physiologic rationale for the use of airway clearance therapy in patients with NMD and a weak cough. ${ }^{51}$ Moreover, there are a number of observational studies supporting the use of cough assistive therapies in this patient population. Thus it is reasonable to recommend airway clearance therapy for these patients, with a goal of increased expectorated sputum, and the therapy should be continued if this goal is achieved.

Respiratory secretions trouble clinicians and patients, and standard practice calls for efforts to clear these from the lungs. An important proportion of respiratory therapists' (and others') time is spent in efforts to remove secretions from the lower respiratory tract. In recent years a variety of techniques for secretion clearance have become available. Despite clinical enthusiasm for many of these by both clinicians and patients, there is sparse high-level evidence demonstrating benefit from many of these techniques. As pointed out by Andrews et al, ${ }^{14}$ there are a number of methodological limitations of the published reports of secretion clearance techniques. Although lack of evidence does not mean lack of benefit, it is desirable to have better evidence to support the practice. Appropriately powered and methodologically sound research is needed. This provides an opportunity for respiratory therapists and others to conduct research on a very important aspect of our practice. To ensure effective therapy for patients and maximize healthcare resources, the scientific basis for airway clearance techniques must be improved.

\section{Summary}

Anecdotally, routine delivery of ACTs, most notably $\mathrm{CPT}$, to non-CF, hospitalized patients is common. However, the burden of delivering prophylactic ACT (ie, potential complications, cost of therapy, overutilization of resources for both staff and patient finances) outweighs the perceived benefit. Indeed, no high-level evidence was found to substantiate significant benefit on any outcome from the use of ACT in this population. ${ }^{14}$ The use of routine prophylactic ACT cannot be supported.

With regard to the NMD population, ACT has traditionally targeted improved cough as a means to prevent and treat pulmonary morbidity. ACT techniques have also been employed during acute respiratory infections to mobilize secretions. However, there is a lack of high-level evidence supporting any of these techniques, despite a large number of observational reports, narrative reviews, and guidelines written on the subject. The Andrews et $\mathrm{al}^{14}$ systematic review found no trials meeting our criteria on the subject, with most research based on crossover or observational design, with small sample sizes, case studies, or anecdotal experience.

When cough is weak, cough assist techniques such as manual or mechanical assisted cough maneuvers may be beneficial. ${ }^{52}$ Low-level evidence from observational studies suggests that a peak cough flow greater than 160 $270 \mathrm{~L} / \mathrm{min}$ is necessary to generate an effective cough. ${ }^{25,26}$ Though the measurement of peak cough flow is more definitive for identifying weak cough, the application of cough assist technique should also be based on the patient's ability to tolerate the therapy, and the effectiveness noted for each individual patient.

Following upper abdominal and thoracic surgery, important pulmonary complications pose substantial risks. Avoidance of these complications is the prudent approach with both appropriate intraoperative ventilation and a postoperative multi-faceted protocol. ${ }^{53-57}$ ACT has been used for the prevention and treatment of postoperative pulmonary complications for many years. However, there are many causes of atelectasis, ${ }^{58}$ and the use of ACT in the setting of atelectasis without retained airway secretions does not appear to be effective. This is particularly true in the setting of upper abdominal and thoracic incisions, where performing these maneuvers is likely to increase pain, which further impairs lung function and cough. Time honored therapies without sufficient evidence should be abandoned in favor of multi-faceted approaches that include patient education, collaborative care, and early ambulation. . $3-57^{-57}$

Routine use of incentive spirometry cannot be supported as a therapy to prevent postoperative complications. CPAP by face mask can alleviate hypoxemia due to low tidal volumes and airway obstruction, and may avoid reintubation, but there is no high-level evidence that this improves airway clearance..$^{59}$ PEP therapy is seen as a simple and less expensive alternative to CPAP. However, the routine use of PEP has no high-level evidence supporting its use, other than in patients with CF.

Respiratory therapists and others on the healthcare team must face the reality that the ACTs commonly provided for hospitalized patients lack support from high-level studies. In this time of cost containment, we are obliged to provide therapy for which there is sufficient evidence for benefit. This lack of evidence for a commonly administered therapy should sound the siren for clinicians, academic institutions, and funding agencies to collaborate on well designed studies to determine which ACTs are beneficial for hospitalized patients. 


\section{ACKNOWLEDGMENT}

The authors wish to acknowledge the important contribution of Dr Jeff Andrews, Ms Nila Sathe, Ms Shanthi Krishnaswami, and Dr Melissa McPheeters of the Vanderbilt Evidence-Based Practice Center.

\section{REFERENCES}

1. Rubin BK. Physiology of airway mucus clearance. Respir Care 2002; 47(7):761-768.

2. Warwick WJ. Mechanisms of mucous transport. Eur J Respir Dis Suppl 1983;64(Suppl 127):162-167.

3. Foster WM. Mucociliary transport and cough in humans. Pulm Pharmacol Ther 2002;15(3):277-282.

4. Zaugg M, Lucchinetti E. Respiratory function in the elderly. Anesthesiol Clin North America 2000;18(1):47-58.

5. Hernandez ML, Harris B, Lay JC, Bromberg PA, Diaz-Sanchez D, Devlin RB, et al. Comparative airway inflammatory response of normal volunteers to ozone and lipopolysaccharide challenge. Inhal Toxicol 2010;22(8):648-656.

6. Chaudri MB, Liu C, Hubbard R, Jefferson D, Kinnear WJ. Relationship between supermaximal flow during cough and mortality in motor neurone disease. Eur Respir J 2002;19(3):434-438.

7. Hadjikoutis S, Wiles CM. Respiratory complications related to bulbar dysfunction in motor neuron disease. Acta Neurol Scand 2001; 103(4):207-213

8. van der Schans CP. Bronchial mucus transport. Respir Care 2007; 52(9): $1150-1158$.

9. Voynow JA, Rubin BK. Mucins, mucus, and sputum. Chest 2009; 135(2):505-512.

10. Rubin BK. Mucus, phlegm, and sputum in cystic fibrosis. Respir Care 2009;54(6):726-732; discussion 732.

11. Lester MK, Flume PA. Airway-clearance therapy guidelines and implementation. Respir Care 2009;54(6):733-750.

12. Hess DR. Airway clearance: physiology, pharmacology, techniques and practice. Respir Care 2007;52(10):1392-1396.

13. Walsh BK, Hood K, Merritt G. Pediatric airway maintenance and clearance in the acute care setting: how to stay out of trouble. Respir Care 2001;56(9):1424-1440.

14. Andrews J, Sathe NA, Krishnaswami S, McPheeters ML. Nonpharmacologic airway clearance techniques in hospitalized patients: a systematic review. Respir Care 2013;58(12):2160-2186.

15. Guyatt G, Gutterman D, Bauman MH, Addrizzo-Harris D, Hylek EM, Phillips B, et al. Grading strength of recommendations and quality of evidence in clinical guidelines: report from an American College of Chest Physicians task force. Chest 2006;129(1):174-181.

16. Hristara-Papadopoulou A, Tsankas J, Diomou G, Papadopoulou O. Current devices of respiratory physiotherapy. Hippokratia 2008;12(4): 211-220.

17. Marks JH. Airway clearance devices in cystic fibrosis. Paediatr Respir Rev 2007;8(1):17-23.

18. Vianello A, Corrado A, Arcaro G, Gallan F, Ori C, Minuzzo M, Bevilacqua M. Mechanical insufflation-exsufflation improves outcomes for neuromuscular disease patients with respiratory tract infection. Am J Phys Med Rehabil 2005;84(2):83-88

19. Antonaglia V, Lucangelo U, Zin WA, Peratoner A, De Simoni L, Capitanio $\mathrm{G}$, et al. Intrapulmonary percussive ventilation improves the outcome of patients with acute exacerbation of chronic obstructive pulmonary disease using a helmet. Crit Care Med 2006;34(12): 2940-2945.

20. Vargas F, Bui HN, Boyer A, Salmi LR, Gbikni-Benissan G, Guenard $\mathrm{H}$, et al. Intrapulmonary percussive ventilation in acute exacerbations of COPD patients with mild respiratory acidosis: a randomized controlled trial [ISRCTN17802078]. Crit Care 2005;9(4):R382-R389.
21. McCool DF, Rosen MJ. Nonpharmacologic airway clearance therapies: ACCP evidence-based clinical practice guidelines. Chest 2006; 129(1 Suppl):250S-259S.

22. Bott J, Blumenthal S, Buxton M, Ellum S, Falconer C, Garrod R, et al; British Thoracic Society Physiotherapy Guideline Development Group. Guidelines for the physiotherapy management of the adult, medical, spontaneously breathing patient. Thorax 2009;64(Suppl 1)i151.

23. Schechter MS. Airway clearance applications in infants and children. Respir Care 2007;52(10):1382-1390; discussion 1390-1391.

24. Benditt JO, Boitano LJ. Pulmonary issues in patients with chronic neuromuscular disease. Am J Respir Crit Care Med 2013;187(10): 1046-1055.

25. Miller RG, Jackson CE, Kasarskis EJ, England JD, Forshew D, Johnston W, et al. Practice parameter update: the care of the patient with amyotrophic lateral sclerosis: drug, nutritional, and respiratory therapies (an evidence-based review): report of the Quality of Standards Subcommittee of the American Academy of Neurology. Neurology 2009;73(15):1218-1235. Erratum in: Neurology 2009;73(24): 2134.

26. Birnkrant DJ, Bushby KMC, Amin RS, Bach JR, Benditt JO, Eagle $\mathrm{M}$, et al. The respiratory management of patient with Duchenne muscular dystrophy: a DMD care considerations working group specialty article. Pediatric Pulmonol 2010;45(8):739-748.

27. Finder JD, Birnkrant D, Carl J, Farber HJ, Gozal D, Iannaccone ST, et al. Respiratory care of the patient with Duchenne muscular dystrophy: ATS Consensus Statement. Am J Respir Crit Care Med 2004;170(4):456-465.

28. Reardon CC, Christiansen D, Barnett ED, Cabral HJ. Intrapulmonary percussive ventilation vs incentive spirometry for children with neuromuscular disease. Arch Pediatr Adolesc Med 2005;159(6): 526-531.

29. Lange DJ, Lechtzin N, Davey C, David W, Heimann-Patterson T, Gelinas D, et al. High-frequency chest wall oscillation in ALS: an exploratory randomized, controlled trial. Neurology 2006;67(6): 991-997.

30. Chaisson KM, Walsh S, Simmons Z, Vender RL. A clinical pilot study: high frequency chest wall oscillation airway clearance in patients with amyotrophic lateral sclerosis. Amyotrophic Lateral Scler 2006; 7(2):107-111.

31. Freitas ER, Soares BG, Cardoso JR, Atallah AN. Incentive spirometry for preventing postoperative complications after coronary pulmonary complications after coronary artery bypass graft. Cochrane Database Syst Rev 2012;(9):CD004466.

32. Guimarães MM, El Dib R, Smith AF, Matos D. Incentive spirometry for prevention of postoperative pulmonary complications in upper abdominal surgery. Cochrane Database Syst Rev 2009;(3):CD006058.

33. Simmons M, Simmons P. Postoperative respiratory care. In: Hess DR, MacIntyre NR, Mishoe SC, Galvin WF, Adams AB. Respiratory care principles and practice, 2nd edition. Sudbury, MA: Jones \& Bartlett; 2012:856-867.

34. Carvalho CR, Paisani DM, Lunardi AC. Incentive spirometry in major surgeries: a systematic review. Rev Bras Fisioter 2011;15(5): 343-350.

35. Smetana GW. Preoperative pulmonary evaluation: identifying and reducing risks for pulmonary complications. Cleveland Clin J Med 2006;73(1 Suppl):S36-S41.

36. Restrepo RD, Wettstein R, Wittnebel L, Tracy M; American Association for Respiratory Care. AARC Clinical Practice Guideline. Incentive spirometry. Respir Care 2011;56(10):1600-1604.

37. Pasquina P, Tramer MR, Granier JM, Walder B. Respiratory physiotherapy to prevent pulmonary complications after abdominal surgery: a systematic review. Chest 2006;130(6):1887-1899. 
38. Mackay MR, Ellis E, Johnston C. Randomised clinical trial of physiotherapy after open abdominal surgery in high risk patients. Aust $\mathrm{J}$ Physiother 2005;51(3):151-159.

39. Denehy L, Carroll S, Ntoumenopoulos G, Jensins S. A randomized controlled trial comparing periodic mask CPAP with physiotherapy after abdominal surgery. Physiother Res Int 2001;6(4)236-250.

40. de Charmoy SB, Eales CJ. The role of prophylactic chest physiotherapy after cardiac valvular surgery: is there one? S Afr J Physiother 2000;56(3):24-28.

41. Fagevik Olsén M, Hahn I, Nordgren S, Lönroth H, Lundholm K. Randomized controlled trial of prophylactic chest physiotherapy in major abdominal surgery. Br J Surg 1997;84(11):1535-1538.

42. Johnson D, Kelm C, To T, Hurst T, Naik C, Gulka I. Postoperative physical therapy after coronary artery bypass surgery. Am J Respir Crit Care Med 1995;152(3):953-958.

43. Johnson D, Kelm C, Thomson D, Burbridget B, Mayers I. The effect of physical therapy on respiratory complications following cardiac valve surgery. Chest 1996;109(3):638-644.

44. Haeffener MP, Ferreira GM, Barreto SS, Arena R, Dall'Ago P. Incentive spirometry with expiratory positive airway pressure reduces pulmonary complications, improves pulmonary function and 6-minute walk distance in patients undergoing coronary artery bypass graft surgery. Am Heart J 2008;156(5):900. e1-e8.

45. Cassidy MR, Rosenkranz P, McCabe K, Rosen JE, McAneny D. I COUGH: Reducing postoperative pulmonary complications with a multidisciplinary patient care program. JAMA Surg 2013;148(8):740-745.

46. Haines KJ, Skinner EH, Berney S. Association of postoperative pulmonary complications with delayed mobilisation following major abdominal surgery: an observational cohort study. Physiotherapy 2013;99(2):119-125.

47. Wren SM, Martin M, Yoon JK, Bech F. Postoperative pneumoniaprevention program for the inpatient surgical ward. J Am Coll Surg 2010;210(4):291-295.

48. Lawrence VA, Cornell JE, Smetana GE. Strategies to reduce postoperative pulmonary complications after noncardiothoracic surgery: systematic review for the American College of Physicians. Ann Intern Med 2006;144(8):596-608.
49. Berlin JA. N-of-1 clinical trials should be incorporated into clinical practice. J Clin Epidemiol 2010;63(12):1283-1284.

50. Wheeler DM. High-frequency chest-wall compression, patient safety, and the n-of-1 construct. Respir Care 2009;54(3):322-323.

51. Benditt JO, Boitano LJ. Pulmonary issues in patients with chronic neuromuscular disease. Am J Respir Crit Care Med 2013;87(10): 1046-1055.

52. Haas CF, Loik P, Gay S. Airway clearance applications in the elderly and in patients with neurologic or neuromuscular compromise. Respir Care 2007;52(10):1362-1381.

53. Lellouche F, Dionne S, Simard S, Bussières J, Dagenais F. High tidal volumes in mechanically ventilated patients increase organ dysfunction after cardiac surgery. Anesthesiology 2012;116(5):1072-1082.

54. Chaiwat O, Vavilala MS, Philip S, Malakouti A, Neff MJ, Deem S, et al. Intraoperative adherence to a low tidal volume ventilation strategy in critically ill patients with preexisting acute lung injury. J Crit Care 2011;26(2):144-149.

55. Hess DR, Kondili D, Burns E, Bittner EA, Schmidt UH. A 5-year observational study of lung-protective ventilation in the operating room: a single-center experience. J Crit Care 2013;28(4):533. e9e15.

56. Severgnini P, Selmo G, Lanza C, Chiesa A, Frigerio A, Bacuzzi A, et al. Protective mechanical ventilation during general anesthesia for open abdominal surgery improves postoperative pulmonary function. Anesthesiology 2013;118(6):1307-1321.

57. Futier E, Constantin JM, Paugam-Burtz C, Pascal J, Eurin M, Neuschwander A, et al. A trial of intraoperative low-tidal-volume ventilation in abdominal surgery. N Engl J Med 2013;369(5): 428-437.

58. Priftis KN, Rubin BK. Atelectasis, middle lobe syndrome and plastic bronchitis. In: Priftis KC, Anthracopoulos MB, Eber E, Koumbourlis AC, Wood RE. Paediatric bronchoscopy. Switzerland: Karger; 2010: 149-155.

59. Aquino ES, Shimura F, Santos AS, Goto DM, Coelho CC, de Fuccio $\mathrm{MB}$, et al. CPAP has no effect on clearance, sputum properties or expectorated volume in cystic fibrosis. Respir Care 2012;57(11): 1914-191. 